Proceedings

\title{
Sensing Catalytic Converters and Filters at Work Using Radio Frequencies ${ }^{+}$
}

\author{
Ralf Moos *, Stefanie Walter, Carsten Steiner and Gunter Hagen \\ Bayreuth Engine Research Center (BERC), Department of Functional Materials, University of Bayreuth, \\ 95447 Bayreuth, Germany \\ * Correspondence: Functional.Materials@uni-bayreuth.de; Tel.: +49-921-55-7401; Fax: +49-921-55-7405 \\ + Presented at the Eurosensors 2018 Conference, Graz, Austria, 9-12 September 2018.
}

Published: 18 December 2018

\begin{abstract}
The state of catalysts and filters plays a key role in automotive exhaust gas aftertreatment. The soot or ash loading of particulate filters (GPF or DPF), the oxygen loading of three-way catalysts (TWC), the amount of stored ammonia in SCR catalysts, or the NOx loading degree in NOx storage catalysts (NSC) are important parameters. Today, they are determined indirectly based on models that are calibrated by gas or pressure sensors in the exhaust pipe. This contribution overviews a novel approach that determines directly the state of the devices by a radio frequency based technique. For that purpose, the housing of the devices serves as a cavity resonator. As "sensing" element, one or two simple antennas are mounted in the catalyst canning. This contactless-obtained information correlates very well with the catalyst or filter state.
\end{abstract}

Keywords: On-board diagnostics (OBD); Exhaust gas aftertreatment; Microwave cavity perturbation; Radio frequency sensor; Selective catalytic reduction (SCR); SCR ammonia storage; Three-way catalyst (TWC); Oxygen storage (OSC); Lambda probe; Particulate filter (DPF; GPF)

The state of catalysts and filters plays a key role in automotive exhaust gas aftertreatment. The soot or ash loading of particulate filters (Gasoline or Diesel Particulate Filters; GPF or DPF), the oxygen loading degree of three-way catalysts (TWC), the amount of stored ammonia in SCR catalysts, or the $\mathrm{NO}_{x}$ loading degree in lean $\mathrm{NO}_{\mathrm{x}}$ traps (LNT; a.k.a. NOx storage catalysts, NSC) are important parameters. Today, they are determined indirectly and/or based on models that are calibrated by gas sensors installed up- or downstream of the catalysts or by differential pressure sensors in the case of filters. In other words, state determination is standard for all exhaust gas aftertreatment devices.

This contribution overviews a novel approach to determine directly the state of the devices by a radio frequency based technique, in the following denoted as "rf technique". For that purpose, the housing of the device serves as a cavity resonator. As "sensing" element, one or two simple antennas, are mounted in the catalyst canning. The electrical properties of the device (ceramic honeycomb incl. coating and storage material) can be measured. Such contactless-obtained information is very well correlated with the catalyst or filter state as will be demonstrated for different exhaust gas aftertreatment systems [1,2].

\section{(1) Three Way Catalyst (TWC)}

For gasoline engine exhaust gas aftertreatment, knowledge of the amount of actually stored oxygen is required to control the air-fuel ratio during operation. The rf technique measures the electrical attenuation that occurs in the oxygen storage component with the removal of oxygen (=transition from $\mathrm{Ce}^{4+}$ to $\left.\mathrm{Ce}^{3+}\right)$, which goes along with an increased number of free charge carriers $\left(=\mathrm{Ce}^{3+}\right)$. This allows to determine directly the amount of stored oxygen with the rf technique. 
The first studies using microwaves to monitor the oxygen balance of a TWC were mentioned in 2003 [3]. However, it took another five years until in 2008 the first measurements in real exhaust gas were published [4]. From then on, many studies were conducted. For instance, it has been shown that even lambda-control is possible without a lambda probe $[5,6]$ and that the optimum operation point with respect to conversion can be found much more precisely [7]. Cross sensitivities to other exhaust gas components do not occur [8]. A suitable signal feature is the resonant frequency of the system, which can be easily determined with just one antenna [9]. The exhaust temperature needs to be considered since the catalyst canning expands as well as the catalyst substrate changes its electrical properties with temperature. This system can even be applied for gasoline particulate filters that are coated with a TWC coating [10]. For aging detection, several operation modes are proposed [11]. It is noteworthy to say that the rf system can be operated also in phases when the engine is turned off (start stop mode, hybrid electric driving mode) [10].

\section{(2) Ammonia SCR-Catalysts and lean $\mathrm{NO}_{x}$ traps}

DeNOx with zeolite-based SCR catalysts requires the exact knowledge of the amount of stored $\mathrm{NH}_{3}$, especially when operated at low temperatures. It has been shown for all types of SCR catalyst materials that this decisive parameter can be determined directly, independently on the feed ratio [12-14]. Recently, even a fully rf-controlled system has been realized $[15,16]$. Besides the resonant frequency, the quality factor is also an appropriate means that even allows control of the system at higher conversion without gas sensor [17].

The NOx loading state of an LNT can be detected, too. Interfering effects to oxygen are a matter of study at the moment, since they may limit the practical applicability [18].

\section{(3) Particulate filters}

The soot load of diesel or gasoline particulate filters can be determined very precisely with this method $[19,20]$. The effect is at least as large as for TWC. Systems are already available from several suppliers. There are already strategies to distinguish between soot and ash loading [21]. Important noise factors are soot humidity and temperature [22]. Unlike systems that are designed for TWC, where an operation in the resonance mode is envisaged, mostly transmission measurements are conducted [23].

\section{References}

1. Moos, R. Microwave-Based Catalyst State Diagnosis-State of the Art and Future Perspectives. SAE Int. J. Engines 2015, 8, 1240-1245, doi:10.4271/2015-01-1042.

2. Moos, R.; Rauch, D.; Votsmeier, M.; Kubinski, D. Review on Radio Frequency Based Monitoring of SCR and Three Way Catalysts. Top. Catal. 2016, 59, 961-969, doi:10.1007/s11244-016-0575-1.

3. Birkhofer, T.; Hofmann, P.; Knezevic, A.; Moos, R.; Plog, C.; Schneider, R. Verfahren zur Erkennung des Zustands eines Katalysators Mittels Mikrowellen. German Patent Specification DE 10358495 B4, 13 December 2003.

4. Moos, R.; Spörl, M.; Hagen, G.; Gollwitzer, A.; Wedemann, M.; Fischerauer, G. TWC: Lambda Control and OBD without Lambda Probe-An Initial Approach; SAE Technical Paper: Warrendale, PA, USA, 2008; doi:10.4271/2008-01-0916.

5. Beulertz, G.; Votsmeier, M.; Herbst, F.; Moos, R. Replacing the lambda probe by radio frequency-based inoperando three-way catalyst oxygen loading detection. In Proceedings of the 14th International Meeting on Chemical Sensors, IMCS 14, Nuremberg, Germany, 20-23 May 2012; pp. 1426-1428, doi:10.5162/IMCS2012/P2.2.7.

6. Schödel, S.; Moos, R.; Votsmeier, M.; Fischerauer, G. SI-Engine Control with Microwave-Assisted Direct Observation of Oxygen Storage Level in Three-Way Catalysts. IEEE Trans. Control Syst. Technol. 2014, 22, 2346-2353, doi:10.1109/TCST.2014.2305576.

7. Beulertz, G.; Votsmeier, M.; Moos, R. Effect of propene, propane, and methane on conversion and oxidation state of three-way catalysts: A microwave cavity perturbation study. Appl. Catal. B 2015, 165, 369-377, doi:10.1016/j.apcatb.2014.09.068.

8. Reiß, S.; Wedemann, M.; Spörl, M.; Fischerauer, G.; Moos, R. Effects of $\mathrm{H}_{2} \mathrm{O}, \mathrm{CO}_{2}$, $\mathrm{CO}$, and flow rates on the RF-based monitoring of three-way catalysts. Sens. Lett. 2011, 9, 316-320, doi:10.1166/s1.2011.1472. 
9. Moos, R. Catalysts as Sensors-A Promising Novel Approach in Automotive Exhaust Gas Aftertreatment. Sensors 2010, 10, 6773-6787, doi:10.3390/s100706773.

10. Dietrich, M.; Jahn, C.; Lanzerath, P.; Moos, R. Microwave based Oxidation State and Soot Loading Determination on Gasoline Particulate Filters with Three-Way Catalyst Coating for Homogenously Operated Gasoline Engines. Sensors 2015, 15, 21971-21988, doi:10.3390/s150921971.

11. Beulertz, G.; Votsmeier, M.; Moos, R. In operando Detection of Three-Way Catalyst Aging by a MicrowaveBased Method: Initial Studies. Appl. Sci. 2015, 5, 174-186, doi:10.3390/app5030174.

12. Rauch, D.; Albrecht, G.; Kubinski, D.; Moos, R. A microwave-based method to monitor the ammonia loading of a vanadia-based SCR catalyst. Appl. Catal. B 2015, 165, 36-42, doi:10.1016/j.apcatb.2014.09.059.

13. Rauch, D.; Kubinski, D.; Cavataio, G.; Upadhyay, D.; Moos, R. Ammonia Loading Detection of Zeolite SCR Catalysts using a Radio Frequency based Method. SAE Int. J. Engines 2015, 8, 1126-1135, doi:10.4271/201501-0986.

14. Rauch, D.; Kubinski, D.; Simon, U.; Moos, R. Detection of the ammonia loading of a Cu Chabazite SCR catalyst by a radio frequency-based method. Sens. Actuators B Chem. 2014, 205, 88-93, doi:10.1016/j.snb.2014.08.019.

15. Dietrich, M.; Hagen, G.; Reitmeier, W.; Burger, K.; Hien, M.; Grass, P.; Kubinski, D.; Visser, J.; Moos, R. Radio-Frequency-Based $\mathrm{NH}_{3}$-Selective Catalytic Reduction Catalyst Control: Studies on Temperature Dependency and Humidity Influences. Sensors 2017, 17, 1615, doi:10.3390/s17071615.

16. Dietrich, M.; Hagen, G.; Reitmeier, W.; Burger, K.; Hien, M.; Grass, P.; Kubinski, D.; Visser, J.; Moos, R. Radio-Frequency-Controlled Urea Dosing for $\mathrm{NH}_{3}-\mathrm{SCR}$ Catalysts: $\mathrm{NH}_{3}$ Storage Influence to Catalyst Performance under Transient Conditions. Sensors 2017, 17, 2746, doi:10.3390/s17122746.

17. Dietrich, M.; Steiner, C.; Hagen, G.; Moos, R. Radio-Frequency-Based Urea Dosing Control for Diesel Engines with Ammonia SCR Catalysts. SAE Int. J. Engines 2017, 10, 1638-1645, doi:10.4271/2017-01-0945.

18. Walter, S.; Ruwisch, L.; Göbel, U.; Hagen, G.; Moos, R. Radio Frequency-Based Determination of the Oxygen and the NOx Storage Level of NOx Storage Catalysts. Top. Catal. 2018, doi:10.1007/s11244-018-1079-y.

19. Sappok, A.; Bromberg, L.; Parks, J.E.; Prikhodko, V. Loading and Regeneration Analysis of a Diesel Particulate Filter with a Radio Frequency-Based Sensor; SAE Technical Paper: Warrendale, PA, USA, 2010; doi:10.4271/2010-01-2126.

20. Nanjundaswamy, H.; Nagaraju, V.; Wu, Y.; Koehler, E.; Sappok, A.; Ragaller, P.; Bromberg, L. Advanced RF Particulate Filter Sensing and Controls for Efficient Aftertreatment Management and Reduced Fuel Consumption; SAE Technical Paper: Warrendale, PA, USA, 2015; doi:10.4271/2015-01-0996.

21. Sappok, A.; Bromberg, L. Radio Frequency Diesel Particulate Filter Soot and Ash Level Sensors: Enabling Adaptive Controls for Heavy-Duty Diesel Applications. SAE Int. J. Commer. Veh. 2014, 7, 468-477, doi:10.4271/2014-01-2349.

22. Feulner, M.; Seufert, F.; Müller, A.; Hagen, G.; Moos, R. Influencing Parameters on the Microwave-Based Soot Load Determination of Diesel Particulate Filters, Top. Catal. 2017, 60, 374-380, doi:10.1007/s11244-016-0626-7.

23. Feulner, M.; Hagen, G.; Hottner, K.; Redel, S.; Müller, A.; Moos, R. Comparative Study of Different Methods for Soot Sensing and Filter Monitoring in Diesel Exhausts. Sensors 2017, 17, 400, doi:10.3390/s17020400.

(C) 2018 by the authors. Licensee MDPI, Basel, Switzerland. This article is an open access article distributed under the terms and conditions of the Creative Commons Attribution (CC BY) license (http://creativecommons.org/licenses/by/4.0/). 